\title{
A Comparative Investigation on Egg Yolk Total Antioxidant Capacity Influencing Relativities to Mycotoxins - Ochratoxins
}

\author{
Davar Kazemi ${ }^{1}$, Arash Chaychi Nosrati², Leila Modiri ${ }^{3}$, Ali Shahriyari ${ }^{4}$ \\ 1, 2, 3 Division of Microbiology, Department of Molecular and Cell Biology, Lahijan Branch, Islamic Azad \\ University, Lahijan, Gilan, Iran. ${ }^{4}$ Division of Biomolecular Research, Department of Clinical Pathobiology, \\ Shahid Chamran University, Ahvaz, Khoozestan, Iran.
}

\section{ABSTRACT}

\section{BACKGROUND}

Ochratoxins include a family of toxic secondary metabolites produced by several species of fungi of the genus aspergillus and penicillium. Mycotoxins ${ }^{1}$ are important environmental pollutants that can be generated in a variety of food and feed components. Nowadays, most mycotoxins can be identified at an acceptable level in terms of legal, veterinary and medical needs. We wanted to compare the egg yolk total antioxidant capacity relativities to mycotoxins ochratoxins (OTA) to determine surges in side effects of human consumption.

\section{METHODS}

Samples were tested by the indirect competitive enzyme-linked immunosorbent assay (ELISA) test kits according to the kit's instructions. Finally, the collected data was analysed using SPSS software and descriptive statistics (contamination ratio, mean and standard deviation) and one-way analysis of variance.

\section{RESULTS}

Ochratoxin in all egg yolk samples of the studied 34 brands showed a minimum of $23.17 \mathrm{ppb}$ and a maximum of $252.80 \mathrm{ppb}$. OTA residues indicate high risk levels to consumers.

\section{CONCLUSIONS}

According to the results, the transfer of mycotoxin metabolites to eggs has been in greater possibilities; therefore, control of mycotoxin contamination in laying hen diets and surveys in food and feed in intense risks is recommended to avoid the presence of mycotoxins in eggs intended for human consumption.

\section{KEY WORDS}

Mycotoxin, Total Antioxidant Capacity (TAC), OTA, Egg Yolk
Corresponding Author: Dr. Arash Chaychi Nosrati, Division of Microbiology (Higher Education), Department of Molecular and Cell Biology, Faculty of Basic Sciences, Lahijan branch, Islamic Azad University, Lahijan, Gilan, Iran.

E-mail: arash.chaichi50@gmail.com

DOI: $10.14260 / j e m d s / 2021 / 150$

How to Cite This Article:

Kazemi D, Nosrati CA, Modiri L, et al. A comparative investigation on egg yolk total antioxidant capacity influencing relativities to mycotoxins - ochratoxins. J Evolution Med Dent Sci 2021;10(10):700704, DOI: $10.14260 / \mathrm{jemds} / 2021 / 150$

Submission 06-06-2020,

Peer Review 14-01-2021,

Acceptance 20-01-2021,

Published 08-03-2021.

Copyright (C) 2021 Davar Kazemi et al. This is an open access article distributed under Creative Commons Attribution License [Attribution 4.0 International (CC BY 4.0)] 


\section{BACKGROUND}

The word mycotoxin is derived from Greek words meaning poison. The advent of mycotoxicology dates back to a mysterious disease reported unknown as Turkey-X.1,2 Mycotoxins, along with other fungal metabolites such as antibiotics, alkaloids, etc., are compounds that are produced by fungal cells in the middle and final stages of filamentous fungal growth, known as secondary metabolites; may appear to be of no use to the fungal cell itself but on the other hand, make the micro environments in pressure for primary metabolites such as amino acids, fatty acids, sugars, nucleic acids, and proteins which are essential for all living organisms. Metabolic processes that lead to the production of secondary metabolites are the final products of secondary metabolism stages while they are structurally relatively small organic compounds with complex chemical structures. $1,3,4$

Such metabolites, mycotoxins, can be classified according to their molecular structures, biosynthetic pathways or bioactivities.1,3-5 The major bioactivities of mycotoxins in metabolic functions in animals are interfering with general metabolism and specially normal performances such as oxidative metabolisms, antioxidant activities, immune responses, general growing and production and some genetic defects which are manifesting by several subclinical or eventually significant clinical signs leading to more efforts to deactivating model of mycotoxins residues in feed and foods. ${ }^{5-}$ 10

Ochratoxins are associated with impaired renal function. As a result, ochratoxins indirectly disrupts every aspects of egg productions such as yolk fatty acids profiles, antioxidant activities, embryonic health, total laying productions as well as shell quality. Shirley and Tohala (1983) reported low quality shells and blood-stained eggs in chicken fed diets containing the toxin, Jewers (1990) reported the presence of thin rubber shells that break more easily than normal during ochratoxin contamination too. Ochratoxins have been reported to cause spots on the surface of the shell as well as low strength of the shell, eventually citrinin and patulin, like aflatoxins, which have been fed separately, have also been shown to reduce eggshell calcium content in laying hens vice versa. Amongst nutritional defects, toxins, have the highest decrease in the calcium content of the eggshell, in addition convers the shape of the eggs and reduces the egg qualities.6,11-15

To study the evaluative levels of ochratoxins in the kidney, liver and bile, Armorini (2015) experimented; egg laying chicken hens were fed with 10 - 200 micrograms per kilogram of OTA impregnated diet for 6 weeks. Collected bile from kidney, liver and gallbladder from all chickens were analysed by high-performance liquid chromatography (HPLC) for OTA detection. Collected oocytes were examined for OTA, 2 days before the start and 2 days after completion. Results showed a corresponding biliary excretion of mycotoxin, with high levels of OTA in the bile after administration while OTA levels in eggs were below the detection limit (LOD) as well as testing sencivities strence, indicated appropriateness of using bile as a major matrix for screening of OTA measurements in laying hens but not rejected egg yolk efficacies as screening samples.

Finally, food health has become an important issue for the poultry products industries. In relation to eggs, the emphasis on food health is on mycotoxins, especially ochratoxins, which cause human malnutritional side effects leading to disease. To increase as much as possible high-level safeties, a growing number of egg-producing companies are adopting egg quality assurance programs parallel to surveyors' institutions that encourage measures for all aspects of egg production to reduce the risk of all mycotoxins as well as ochratoxin-A contamination in egg and egg by products, including measures to ensure that poultry feed and their products are free of mycotoxins or having lower tolerable limit doses (LTD). ${ }^{1-}$ $5,9,10,16$

\section{METHODS}

This cross-sectional study was conducted from April 2015 to August 2018. Samples were tested by the test kit and the ELISA procedure according to the suggested instructions of the kit. Finally, the collected data was analysed using SPSS software and descriptive statistics (contamination ratio, mean and standard deviation), one-way analysis of variances and numerical parametric / nonparametric statistical analysis.

\section{Materials in the Test Kit}

Each kit made by the Dutch company (R-Biopharm AG, Darmstadt, Germany, RIDASCREEN $\left.{ }^{\circledR}\right)$ for quantitative analysis OTA 30 / 15 tests) in vitro enzyme immunoassays (point to point, linear, cubic) applied with quantification ranged approximately 2.5 - 50 ppb detection limits as well as $100 \%$ recovery rates (OTA $100 \%$, OTC $44 \%$, OTB $14 \%$ specifies rates) contained following materials: 96-well microtiter (12 strips with 8 wells each) coated. Seven each $1.3 \mathrm{~mL}$ OTA standard solution vials containing with concentrations equal to: $0 \mathrm{ng} / \mathrm{mL}$ (ppt, standard zero), $50 \mathrm{ng} / \mathrm{mL}, 100 \mathrm{ng} / \mathrm{mL}$, $300 \mathrm{ng} / \mathrm{mL}, 900 \mathrm{ng} / \mathrm{mL}, 1800 \mathrm{ng} / \mathrm{mL}$, in aqueous solutions. One concentrated $0.7 \mathrm{~mL}$ vial lyophilised peroxidase conjugated antibody solution, $7 \mathrm{~mL}$ antibody conjugate dilution buffer vial, $10 \mathrm{~mL}$ vial substrate / chromogen (tetra methyl benzidine, red stained), $14 \mathrm{~mL}$ stop solution vial (1 $\mathrm{N}$ sulfuric acid) and wash buffer salted powder for $10 \mathrm{mM}$ pbs / pH 7.4+ 0.05 tween 20 solution to dilute the samples, reagents and standards at one solution / vial with carpet volume of 30 $\mathrm{mL}$.

\section{Preparation of Reagents}

Before starting laboratory tests, some ingredients need to be prepared and some are ready to use. After washing / disinfecting, eggs have been dealbuminated then homogenised and $2 \mathrm{~mL} / 2.5 \mathrm{~mL}$ mixed with $1 \mathrm{~N} \mathrm{HCL}+4 \mathrm{~mL}$ dichloromethane (in centrifugal screw cap vial), shook for 5 minutes followingly centrifuged; $15 \mathrm{~min} / 3500 \mathrm{~g} / 15^{\circ}$ centigrade temperatures. Discarding supernatants entire sedimented layer paper filtrated till sample cakes to be collected. Repeatedly procedures have been done in both phases, combined then diluted solutions with $0.75 \mathrm{~mL} 1 \mathrm{~N} \mathrm{HCL}+2 \mathrm{~mL}$ dichloromethane shaking for $10 \mathrm{~min} /$ centrifuged $5 \mathrm{~min} /$ $3500 \mathrm{~g} / 15^{\circ} \mathrm{C}$. Using entire layer for evaporating completely dried at $60^{\circ} \mathrm{C}$ then resolved all in $1 \mathrm{~mL} 0.13 \mathrm{M}$ sodium hydrogen carbonate buffer up to be used as $50 \mu \mathrm{l}$ per well. Concentrated conjugates have diluted 1:10 for reconstitution in dilution buffers. Entire buffer salt powders dissolved in $1000 \mathrm{~mL}$ DW to be ready for $4-6 \mathrm{w}$ at $4-8^{\circ} \mathrm{C}$. Conjugate 
solution and antibody solution are available in lyophilized kit and in order to use, $4 \mathrm{~mL}$ of dilution buffer should be added to them and shaken vigorously and stored in a dark place until use. The chromogenic substrate solution in the kit is ready to use and must be stored at room temperature before use.

\section{Sensitivity and Specificity of the Experiment}

The sensitivity of the test varies between $2.5-50 \mathrm{ppb}$ depending on the test matrix. The specificity of this test is based on interactions with $6-3$ TAC statistical analysis method.

\section{Measurement of Total Antioxidant Capacity}

This test is based on the regenerative capability of the sample to regenerate ferric ions to ferrous ions and to form a blue $\mathrm{Fe}^{+}$ -TPTZ complex, which can be evaluated by spectrophotometric method. In order to calculate the total antioxidant activity, first the standard diagram of absorption of different concentrations of iron was obtained and then using the line equation $\mathrm{Y}=\mathrm{ax}+\mathrm{b}$, the total antioxidant capacity of unknown samples was obtained.

\section{Statistical Analysis}

The collected data were analysed using SPSS software using descriptive statistics (contamination ratio, mean, standard deviation and trimmed mean $5 \%$ ) and one-way analysis of variance, T-tests (paired samples statistic differences), Pearson's 2-tailed and parametric nonparametric evaluations finally 2-way ANOVA.

\section{RESULTS}

\section{Evaluation of OTA Levels in All Egg Yolk Samples}

In the study of the amount of ochratoxin in 630 egg yolk samples of the 30 studied brands, the minimum value was $23.17 \mathrm{ppb}$ and the maximum was $252.80 \mathrm{ppb}$ in the $\mathrm{p} / \mathrm{p}$ analysis, as well as the minimum value was $35.50 \mathrm{ppb}$ and the maximum was 227.10 in the cub analysis. The average was 29.34 and the maximum was 239.95 . The improved mean with
5 \% error (trimmed mean 5 \%) of 114. 294 (P / P), 108. 5811 (cub) and 111.6994 showed the mean measured values of ochratoxin. The highest amount of ochratoxin measured was 227.10 - 195.88 (cub) and the average was $210.09-239.95$ in samples $85,11,70,111$ and 104. Which include brands no. 7, $1,6,8$ and 8 . The lowest values of ochratoxin measured were $90-67-50$ - 35 and the average was $29.34-66.45$ in samples $22,74,154,58$ and 75, which include brands 2, 6, 12, 5 and 6 . Due to fiduciary, brand names are hidden.

\section{Pearson Analysis and Ochratoxin Levels}

Evaluation of the correlation between Pearson analysis and the measurement of ochratoxin by $\mathrm{P} / \mathrm{P}$ and Wilcoxon methods showed a statistical relationship (PC: 0.997). This correlation between the mean value of total ochratoxin measured by P / P and cub (PC: 0.999) was also statistically significant (sig: 0.000) (Figure 1, Table 1 and 2).

This view is also considered in the analysis of Wilcoxon analysis between the level of ochratoxin P / P and ochratoxin cub (Z: - 9.532 / sig: 0.000) as well as ochratoxin P / P and ochratoxin total means (Z: - 9.532 / sig: 0.000). The cubic toxin levels and the mean total ochratoxin (Z: - 9.532 / sig: 0.000) have also been observed to be correlated thus, strongly confirm the above conclusions (Table 2 and 3 ).

Therefore, it can be found that regardless of the analysis and processing of values measured by competitive indirect ELISA method, all data obtained by different methods of numerical functions in determining the amount of toxin will have the same behaviour in numerical analysis with statistical methods (Table 1, 2 and 3).

Regarding the measurement of TAC variables with the level of ochratoxin (cub), only the amount of TAC per ng / g had a statistically significant correlation and the same was not observed in relation to the average value of total ochratoxins with TAC per unit ng / g (Figure 1 and 2).

Approved TAC quantities based on values of $\mathrm{ng} / \mathrm{g}$ relativities to $\mathrm{nMol} / \mathrm{g}$ regarding to Wilcoxon statistical analysis showed that there is an opposite meaning correlation (TAC mean nmol / g-TAC mean ng / g: Z: - 6.852 / sig: 0.000, TAC mean nmol / g-TAC ng / g: Z: -6.361 / sig: 0.000 and TAC nmol / g-TAC ng / g: Z: - 5.884 / sig: 0.000) ensure us to the role of TAC quantitation based on that scales (Figure 2).

\begin{tabular}{|c|c|c|c|c|c|c|c|c|c|}
\hline Mean \pm SD & & $\begin{array}{l}\text { PL-C14 } \\
\text { och-p-p }\end{array}$ & $\begin{array}{l}\text { PL-C } 15 \\
\text { och-p-p }\end{array}$ & $\begin{array}{l}\text { PL-C16 } \\
\text { och-p-p }\end{array}$ & $\begin{array}{c}\text { PL-C } 17 \\
\text { och-p-p }\end{array}$ & $\begin{array}{l}\text { PL-C } 18 \\
\text { och-p-p }\end{array}$ & $\begin{array}{l}\text { PL-C } 20 \\
\text { och-p-p }\end{array}$ & $\begin{array}{l}\text { PL-C } 22 \\
\text { och-p-p }\end{array}$ & $\begin{array}{l}\text { PL-C24 } \\
\text { och-p-p }\end{array}$ \\
\hline \multirow[b]{2}{*}{$40.364 \pm 4.279$} & $\mathrm{Z}^{\mathrm{a}}$ & $-10.764^{b}$ & $-10.764 b$ & $-10.764^{b}$ & $-10.764^{b}$ & $-10.764^{b}$ & $-10.764^{b}$ & $-10.764^{b}$ & $-10.764 b$ \\
\hline & $\begin{array}{c}\text { Asymp. } \\
\text { Siga. (2-tailed) }\end{array}$ & .000 & .000 & .000 & .000 & .000 & .000 & .000 & .000 \\
\hline
\end{tabular}

\begin{tabular}{|c|c|c|c|c|c|c|c|c|c|}
\hline Mean \pm SD & & $\begin{array}{c}\text { PL-C14 } \\
\text { och-cub }\end{array}$ & $\begin{array}{c}\text { PL-C }_{15} \\
\text { och-cub }\end{array}$ & $\begin{array}{c}\text { PL-C16 } \\
\text { och-cub }\end{array}$ & $\begin{array}{c}\text { PL-C17 } \\
\text { och-cub }\end{array}$ & $\begin{array}{c}\text { PL-C18 } \\
\text { och-cub }\end{array}$ & $\begin{array}{c}\text { PL-C20 } \\
\text { och-cub }\end{array}$ & $\begin{array}{c}\text { PL-C22 } \\
\text { och-cub }\end{array}$ & $\begin{array}{c}\text { PL-C24 } \\
\text { och-cub }\end{array}$ \\
\hline \multirow[b]{2}{*}{$33.324 \pm 3.532$} & $\begin{array}{c}\mathrm{Z} \\
\text { Asymp. }\end{array}$ & $-10.764^{b}$ & $-10.764^{b}$ & $-10.764^{b}$ & $-10.764^{b}$ & $-10.764^{b}$ & $-10.764^{b}$ & $-10.764^{b}$ & $-10.764^{b}$ \\
\hline & $\begin{array}{c}\text { Siga. } \\
\text { (2-tailed) }\end{array}$ & .000 & .000 & .000 & .000 & .000 & .000 & .000 & .000 \\
\hline
\end{tabular}




\begin{tabular}{|c|c|c|c|c|c|c|c|c|}
\hline & $\begin{array}{c}\text { PL-C } 14 \\
\text { och-mean }\end{array}$ & $\begin{array}{c}\text { PL-C } 15 \text { och- } \\
\text { mean }\end{array}$ & $\begin{array}{c}\text { PL-C } 16 \\
\text { och-mean }\end{array}$ & $\begin{array}{c}\text { PL-C } 17 \\
\text { och-mean }\end{array}$ & $\begin{array}{c}\text { PL-C } 18 \\
\text { och-mean }\end{array}$ & $\begin{array}{c}\text { PL-C } \mathrm{C}_{20} \text { och- } \\
\text { mean }\end{array}$ & $\begin{array}{c}\text { PL-C22 och- } \\
\text { mean }\end{array}$ & $\begin{array}{c}\text { PL-C24 och- } \\
\text { mean }\end{array}$ \\
\hline $\begin{array}{c}\text { Z } \\
\text { Asymp. }\end{array}$ & $-10.764^{b}$ & $-10.764^{b}$ & $-10.764^{b}$ & $-10.764 \mathrm{~b}$ & $-10.764^{b}$ & $-10.764^{b}$ & $-10.764^{b}$ & $-10.764 \mathrm{~b}$ \\
\hline $\begin{array}{c}\text { Siga. } \\
\text { (2-tailed) }\end{array}$ & .000 & .000 & .000 & .000 & .000 & .000 & .000 & .000 \\
\hline
\end{tabular}
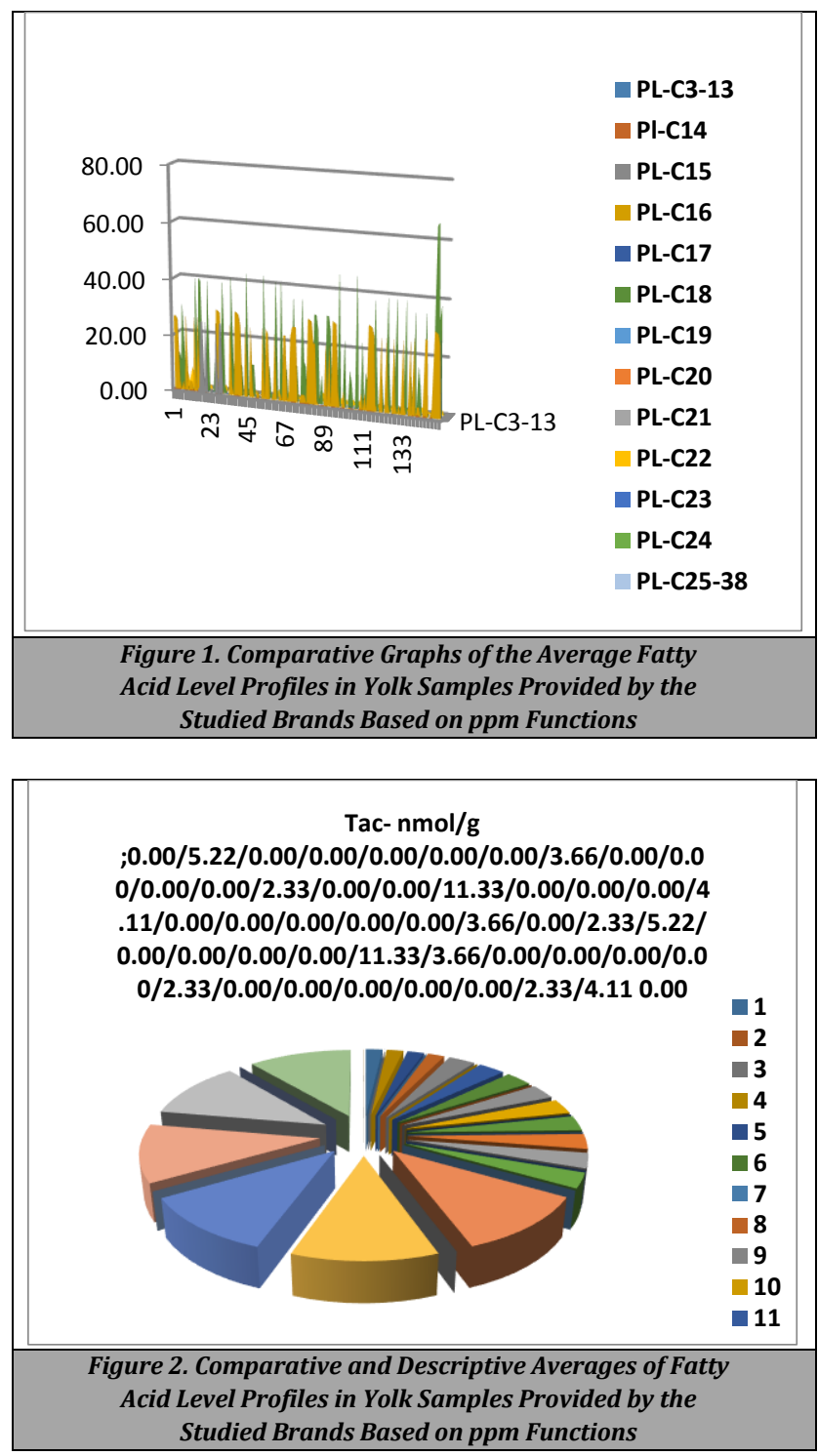

Examination of any nonparametric relationship between the mean amount of ochratoxin and fatty acids shows that there is a statistically significant and similar correlation between all fatty acids. This finding is similarly observed with a $\mathrm{Z}$ factor equal to the amount of ochratoxin (cub) and all fatty acids. Definitively as mentioned before there are a potent influencing effort by structural unsaturated chemical bonds in egg yolk fatty acid compositions, Pearson statistical analysis cleared that a 2-way statistical correlation between TAC ng / g and $\mathrm{C}_{14}$ (PC: 0.228 / sig: 0.000), $\mathrm{C}_{16}$ (PC: 0.163 / sig: 0.044), $\mathrm{C}_{18}$ (PC: 0.228 / sig: 0.004), $\mathrm{C}_{20}$ (PC: 0.302 / sig: 0.042) and $\mathrm{C}_{22}$ (PC: $0.398 / \operatorname{sig} 0$.

\section{DISCUSSION}

Due to the importance of mycotoxins in the edible animals, their products and human food chain; in many countries to protect consumers against the harmful effects of mycotoxins in food, special regulations have been enacted to enable inspective activities and surveillance projects to verify and guarantees feed and food safety as well as securities. Due to international affairs notifications Iranian ${ }^{\mathrm{s}}$ General Directory of Food and Drug Control and Administrations has set the permissible limit of some mycotoxins for animal and human feeds and foods consumption at LTD in $\mu \mathrm{g} / \mathrm{gr}-\mathrm{ng} / \mathrm{gr}$ even though $50 \mathrm{ppb}$ for total permissible limit of OTA. The European Union and the Food and Drug Administration have also set the permissible levels of OTA in various food products, including animal products. ${ }^{1-5,9,10,16}$

Due to the importance of mycotoxins in various foodstuffs, including animal feed, and human foods several studies have been conducted in Iran and other countries. ${ }^{1-5,9,10}$ According to Hadizadeh Moallem et al. in Mazandaran province, $27.1 \%$ of the samples collected in summer and $42.7 \%$ of the samples collected in winter showed contamination rates more than 5 micrograms per kilogram of ochratoxins. The average pollution in winter and summer are reported to be 5.9 and 3.83, respectively. Therefore, it is expected that the consumption of feed with the above toxic content by laying hens can be a risk factor in egg and egg consumer's health (2, 13). There are several investigators aimed antioxidant potential capacities of egg specially the yolk unsaturated fatty acids reflecting by nutritional efforts and influencing by mycotoxins as constant adverse effects visualised in egg quality and make it a drastic potential causative agent for mycotoxins residues transfer to human food cycle chain. $2,6,17,18,7,8,11-16$

By duration of Wilcoxon analysis between the values of ochratoxin (p / p) and ochratoxin (cub) (Z: - 9.532 / sig: $0.000)$, ochratoxin ( $\mathrm{p} / \mathrm{p}$ ) and total ochratoxin means (Z: 9.532 sig: 0.000 ) as well as ochratoxin (cub) and total ochratoxin means (Z: - 9.532 / sig: 0.000) have also been observed and strongly confirmed the above conclusions. Therefore, according to the results, it can be said that diets contaminated with ochratoxin such as egg laying poultries diets up to their products which are widely consumed by humans, interferes with metabolism, and make a role by adversely effects on the oxidative capacity of yolks. $2,5,9,10$

\section{CONCLUSIONS}

Consuming OTA in diets increases liver LPO and free hydroxyl radicals continually elevating lipid peroxidation due to oxidative reactivities along with increasing the toxin 
concentration of accumulative efforts leading to caspase- 3 and Bax programmed cell death known as apoptosis.

Therefore, observing the statistical analysis, the findings obtained regarding the amount of OTA toxin in relation to TAC did not find any statistically significant correlation. So, it can be concluded that in the study population, the decrease in antioxidant capacity of the studied egg yolks has a statistically significant correlation with the mean of the only aflatoxin and the level of aflatoxin assays with (cub and $p / p$ ) functions and other mycotoxins cannot cause a measurable decrease in TAC in the amounts found in this study. (Figure 2, Table 3)

According to the results the transfer of mycotoxin metabolites to eggs has been possible at-risk inducing levels and therefore, control of mycotoxin contamination in laying hen diets and all their products are recommended to avoid the presence of mycotoxins in eggs. intended a notify able surge for human consumption.

Data sharing statement provided by the authors is available with the full text of this article at jemds.com.

Financial or other competing interests: Authors report grants from Islamic Azad University, lahijan Branch.

Disclosure forms provided by the authors are available with the full text of this article at jemds.com.

Authors thank the research and technology deputy of the Islamic Azad University, lahijan branch for permissions and financial support, Dr. S. Shokri Fashtali for statistical analysis, and Div. Biomolecular Chemistry, Department of Clinical Pathobiology, Sh. Chamran University for technical supports.

\section{REFERENCES}

[1] Abdelsalam EB, el-Tayeb AE, Nor Eldin AA, et al. Aflatoxicosis in fattening sheep. Vet Rec 1989;124(18):487-8.

[2] Patterson DS, Roberts BA. Aflatoxin metabolism in duckliver homogenates: the relative importance of reversible cyclopentenone reduction and hemiacetal formation. Food Cosmet Toxicol 1972;10(4):501-12.

[3] Applebaum RS, Brackett RE, Wiseman DW, et al. Responses of dairy cows to dietary aflatoxin: feed intake and yield, toxin content and quality of milk of cows treated with pure and impure aflatoxin. J Dairy Sci 1982;65(8):1503-8.

[4] Hamblin AM. A focus on aflatoxin contamination. University of Illinoise 2001: p. 1997-2001.

[5] Patterson DSP, Anderson PH. Recent aflatoxin feeding experiments in cattle. Vet Rec 1982;110(3):60.

[6] Chen W, Wang S, Zhang HX, et al. Optimization of dietary zinc for egg production and antioxidant capacity in Chinese egg-laying ducks fed a diet based on corn-wheat bran and soybean meal. Poult Sci 2017;96(7):2336-43.
[7] Ruan D, Fouad AM, Fan Q, et al. Effects of dietary methionine on productivity, reproductive performance, antioxidant capacity, ovalbumin and antioxidant-related gene expression in laying duck breeders. Br J Nutr 2018;119(2):121-30.

[8] El-Senousey HK, Chen B, Wang JY, et al. Effects of dietary Vitamin C, Vitamin E and alpha-lipoic acid supplementation on the antioxidant defense system and immune-related gene expression in broilers exposed to oxidative stress by dexamethasone. Poult Sci 2018;97(1):30-8.

[9] Gardner HK, Koltun SP, Dollear FG, et al. Inactivation of aflatoxins in peanut and cottonseed meals by ammoniation. J Am Oil Chem Soc 1971;48(2):70-3.

[10] Samarajeewa U, Sen AC, Fernando SY, et al. Inactivation of aflatoxin B1 in corn meal, copra meal and peanuts by chlorine gas treatment. Food Chem Toxicol 1991;29(1):41-7.

[11] Wang J, Yang Z, Celi P, et al. Alteration of the antioxidant capacity and gut microbiota under high levels of molybdenum and green tea polyphenols in laying hens. Antioxidants 2019;8(10):503.

[12] Kullu SS, Das A, Bajpai SK, et al. Egg production performance, egg yolk antioxidant profile and excreta concentration of corticosterone in golden pheasants (Chrysolophus pictus) fed diets containing different levels of green vegetables. J Anim Physiol Anim Nutr (Berl) 2017;101(5):e31-42.

[13] Surai PF, Kochish II, Romanov MN, et al. Nutritional modulation of the antioxidant capacities in poultry: the case of vitamin E. Poult Sci 2019;98(9):4030-41.

[14] Hargitai R, Nyiri Z, Eke Z, et al. Effects of temperature and duration of storage on the stability of antioxidant compounds in egg yolk and plasma. Physiol Biochem Zool 2016;89(2):161-7.

[15] Reis JH, Gebert RR, Barreta M, et al. Addition of grape pomace flour in the diet on laying hens in heat stress: Impacts on health and performance as well as the fatty acid profile and total antioxidant capacity in the egg. J Therm Biol 2019;80:141-9.

[16] Surai PF. Antioxidants in poultry nutrition and reproduction: an update. Antioxidants (Basel) 2020;9(2):105.

[17] Dong XF, Zhai QH, Tong JM. Dietary choline supplementation regulated lipid profiles of egg yolk, blood and liver and improved hepatic redox status in laying hens. Poult Sci 2019;98(8):3304-12.

[18] Surai PF, Kochish II, Fisinin VI, et al. Antioxidant defence systems and oxidative stress in poultry biology: an update. Antioxidants (Basel) 2019;8(7):235. 